\title{
CNS-border associated macrophages respond to acute ischemic stroke attracting granulocytes and promoting vascular leakage
}

Jordi Pedragosa ${ }^{1,2}$, Angélica Salas-Perdomo ${ }^{1}$, Mattia Gallizioli, ${ }^{1,2}$, Roger Cugota ${ }^{1,7}$, Francesc Miró-Mur ${ }^{2,3}$, Ferran Briansó ${ }^{4,5}$, Carles Justicia ${ }^{1,2}$, Fernando Pérez-Asensio ${ }^{1}$, Leonardo Marquez-Kisinousky', Xabier Urra ${ }^{2,6}$, Anna Gieryng ${ }^{6}$, Bozena Kaminska ${ }^{6}$, Angel Chamorro ${ }^{2,6}$ and Anna M. Planas ${ }^{1,2^{*}}$ (D)

\begin{abstract}
The central nervous system (CNS) contains several types of immune cells located in specific anatomic compartments. Macrophages reside at the CNS borders surrounding the brain vessels, in leptomeningeal spaces and the choroid plexus, where they interact with the vasculature and play immunological surveillance and scavenging functions. We investigated the phenotypic changes and role of these macrophages in response to acute ischemic stroke. Given that CD163 expression is a hallmark of perivascular and meningeal macrophages in the rat and human brain, we isolated $\mathrm{CD}_{163^{+}}$brain macrophages by fluorescence activated cell sorting. We obtained $\mathrm{CD}_{163^{+}}$cells from control rats and $16 \mathrm{~h}$ following transient middle cerebral artery occlusion, after verifying that infiltration of $\mathrm{CD}_{163^{+}}$peripheral myeloid cells is negligible at this acute time point. Transcriptome analysis of the sorted $\mathrm{CD}_{163^{+}}$cells identified ischemia-induced upregulation of the hypoxia inducible factor-1 pathway and induction of genes encoding for extracellular matrix components and leukocyte chemoattractants, amongst others. Using a cell depletion strategy, we found that CNS border-associated macrophages participate in granulocyte recruitment, promote the expression of vascular endothelial growth factor (VEGF), increase the permeability of pial and cortical blood vessels, and contribute to neurological dysfunction in the acute phase of ischemia/reperfusion. We detected VEGF expression surrounding blood vessels and in some $\mathrm{CD} 163^{+}$perivascular macrophages in the brain tissue of ischemic stroke patients deceased one day after stroke onset. These findings show ischemia-induced reprogramming of the gene expression profile of $\mathrm{CD}_{163^{+}}$macrophages that has a rapid impact on leukocyte chemotaxis and blood-brain barrier integrity, and promotes neurological impairment in the acute phase of stroke.
\end{abstract}

Keywords: Perivascular macrophages, Subpial macrophages, Hypoxia, Leukocytes, Brain, Ischemia

\section{Introduction}

The central nervous system (CNS) contains different subsets of myeloid cells under steady-state conditions. Microglia reside in the brain parenchyma whereas macrophages

\footnotetext{
* Correspondence: anna.planas@iibb.csic.es

'Department of Brain Ischemia and Neurodegeneration, Institut

d'Investigacions Biomèdiques de Barcelona (IIBB)-Consejo Superior de Investigaciones Científicas (CSIC), Rosselló 161, E-08036 Barcelona, Spain

${ }^{2}$ Àrea de Neurociències, Institut d'Investigacions Biomèdiques August Pi i

Sunyer (IDIBAPS), Rosselló 161, E-08036 Barcelona, Spain

Full list of author information is available at the end of the article
}

remain at the CNS borders. CNS border-associated macrophages (BAMs) include cells resident in the perivascular spaces of brain vessels, lining the meninges, and the choroid plexus. BAMs carry out scavenger functions and are fully competent to present antigen to lymphocytes $[6,12$, $27,34,37]$. BAMs derive from hematopoietic progenitors that populate the brain at embryonic stages and are not replaced by bone-marrow derived cells under physiological conditions $[18,19]$. Little is known about the function of BAMs under pathological conditions but several lines of evidence support their involvement in the

(c) The Author(s). 2018 Open Access This article is distributed under the terms of the Creative Commons Attribution 4.0 International License (http://creativecommons.org/licenses/by/4.0/), which permits unrestricted use, distribution, and reproduction in any medium, provided you give appropriate credit to the original author(s) and the source, provide a link to the Creative Commons license, and indicate if changes were made. The Creative Commons Public Domain Dedication waiver (http://creativecommons.org/publicdomain/zero/1.0/) applies to the data made available in this article, unless otherwise stated. 
pathogenesis of brain diseases [13]. Perivascular macrophages are protective during bacterial meningitis [44], and participate in the clearance of vascular Amyloid- $\beta$ (A $\beta$ ) deposition in mouse models of Alzheimer's disease [23, 36, 54]. However, these cells also mediate oxidative stress and cerebrovascular dysfunction induced by $A \beta$ [39]. They contribute to endothelial, neurovascular, and cognitive dysfunction in several models of hypertension [14, 41], and exacerbate the clinical symptoms in a model of experimental allergic encephalomyelitis [43]. A recent study in the mouse using high-dimensional single-cell cytometry and fate mapping identified different subsets of BAMs and showed differential responses of BAMs compared to other brain myeloid cell populations during aging, experimental autoimmune encephalomyelitis, and in a model of Alzheimer's disease [37].

Ischemic stroke is a frequent disease and one of the main causes of death and permanent disability worldwide [15]. Lack of adequate blood supply to a brain region causes brain damage and triggers sterile inflammation and innate immune responses $[5,26]$ that are considered as putative targets for therapeutic intervention [4]. While the responses of microglia to ischemic stroke have been extensively studied [33], those of BAMs remain largely unknown. Nevertheless, BAMs might be important in cerebrovascular diseases because they are located at the interface between the blood vessels, the brain parenchyma, and the immune system. In humans [28] and rats [34], perivascular and meningeal macrophages have been classically characterised by the expression of CD163, a membrane scavenger receptor belonging to the cysteine-rich superfamily [31] that is involved in the response to inflammation [10]. In this study, we investigated the phenotype and function of $\mathrm{CD} 163^{+}$BAMs in the acute phase of cerebral ischemia/reperfusion in rats.

\section{Materials and methods}

An extended version of the methods is available in the Additional file 1.

\section{Experimental brain ischemia}

Focal brain ischemia was induced in adult male Sprague-Dawley rats (280-320 g body weight) by 1 -h intraluminal occlusion of the right middle cerebral artery (MCAo) with reperfusion. Briefly, rats were anaesthetised with isoflurane and cortical cerebral perfusion was measured with a laser-Doppler flowmeter (PF4001 Master, Perimed). Body temperature was maintained at $37.5{ }^{\circ} \mathrm{C}$ during surgery with a heating blanket connected to a rectal probe. The MCA was occluded with a filament (Doccol \#403912PK10Re). Rats were excluded from the study if the mean drop in cerebral perfusion during ischemia did not reach at least $65 \%$ of the basal value. Overall mortality after ischemia was $<10 \%$. A neurological test on a nine-point scale $(0=$ no deficit to $9=$ highest handicap $)$ was performed at $24 \mathrm{~h}$. We scored: (i) spontaneous activity (moving/exploring $=0$, moving without exploration $=1$, no moving or only when pulled by the tail $=2$ ); (ii) circling to the left (none $=0$, circling when elevated by the tail and pushed or pulled $=1$, spontaneous circling $=2$, circling without displacement $=3$ ); (iii) resistance to left (contralateral) forepaw stretching (full resistance $=0$, rats offer some resistance but they allow stretching $=1$, rats offer no resistance $=2$ ), and (iv) the parachute reflex (symmetrical = 0 , asymmetrical $=1$, contralateral forelimb retracted $=2$ ). The brain was imaged $24 \mathrm{~h}$ after MCAo with MRI in a 7.0 T horizontal animal scanner (BioSpec, Bruker BioSpin, Ettlingen, Germany). Brain lesions were evaluated by $\mathrm{T} 2$ mapping and lesion volume was measured with ImageJ.

\section{Drug administration}

Anesthetized rats (isoflurane) received an i.c.v. injection of $30 \mu \mathrm{l}$ liposomes containing either clodronate $(5 \mu \mathrm{g} / \mu \mathrm{l})$, or PBS as the vehicle (ClodronateLiposomes.com, Haarlem, The Netherlands) in the left ventricle. Treatment was randomly allocated according to a randomization list generated at the beginning of each set of experiments. Each treatment received a code that did not reveal its identity. Drug administration and all further interventions and measurements were carried out in a blinded fashion. Ischemia was induced 4 days after drug administration.

\section{Flow cytometry}

Fresh brain tissue was processed with the Neural Tissue Dissociation Kit (P) (\#130-092-628, Miltenyi Biotec). A 30$0 \%$ percoll gradient was used to remove myelin and cell debris to obtain a single-cell suspension. The pellet was washed and stained with the life/death fixable cell staining Aqua (ThermoFisher Scientific), and cells were immunostained with anti-CD11b (clone OX-42, Alexa Fluor647; AbDSerotec or PerCP-Cy5.5; BioLegend) at 1:40 dilution, anti-CD163 (clone ED2, FITC or PE, AbdSerotec) diluted 1:20, anti-CD45 (clone OX-1 labelled with PE-Cy7, BioLegend, or Alexa Fluor 488 AbdSerotec) diluted 1:50, anti-granulocytes (clone REA535, APC-Vio770, Miltenyi Biotec) diluted 1:50, anti-CD3 (clone G4.18, PE, BD Pharmingen) diluted 1:100, anti-CD4 (clone OX-35, BV711, BD Biosciences) diluted 1:200, anti-CD8 (clone OX-8, Vioblue, Miltenyi-Biotec) diluted 1:200, anti-CD161 (clone 3.2.3, APC, Biolegend) diluted 1:200, anti- $\gamma \delta T C R$ (clone V65, APC-Vio770, Miltenyi-Biotec) diluted 1:100, and anti-CD25 (clone OX-39, FITC, BD Pharmingen) diluted 1:100. We used Flow-count Fluorospheres (Beckman-Coulter) for absolute cell counting. Data were acquired in a BD LSRFortessa SORP flow cytometer (BD Biosciencies) using the BD Diva software (BD Biosciences) and were analysed with Flowjo v10 software (FlowJo). 


\section{Cell sorting}

$\mathrm{CD}_{163}{ }^{+}$macrophages and microglia were isolated from the control rat brain and from the brain $16 \mathrm{~h}$ post-ischemia using fluorescence activated cell sorting (FACS). Briefly, the right brain hemisphere was processed with the Neural Tissue Dissociation Kit and a percoll gradient, as described above for flow cytometry, and single cells were immunostained with CD11b and CD163.

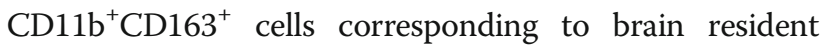

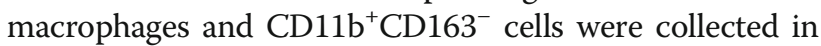
RNAse-free PBS using Aria II cell sorter (BD Biosciences). We verified the purity of the sorted cell populations by flow cytometry in independent experiments.

\section{RNA extraction}

RNA was extracted from samples of FACS-sorted CD163 ${ }^{+}$ macrophages and FACS-sorted $\mathrm{CD}_{163}{ }^{-}$microglia with PureLink $^{\text {TM }}$ RNA Micro Kit (\#12183016, Invitrogen). On-column DNAse step was performed to avoid genomic DNA contamination. RNA purity was assessed by RNA Pico Chip BioAnalyzer 2100 (Agilent). RNA was also extracted from brain tissue samples with the PureLink ${ }^{\mathrm{TM}}$ RNA Mini Kit (\#12183018A, Invitrogen) using Trizol $^{\circledR}$ Reagent (Life Technologies). In this case, we assessed the RNA quantity and quality using a ND-1000 micro-spectrophotometer (NanoDrop Technologies).

\section{qRT-PCR}

Total RNA was reverse-transcribed using a mixture of random primers (High Capacity cDNA Reverse Transcription kit, Applied Biosystems). For brain tissue, $1000 \mathrm{ng}$ of total RNA were reverse-transcribed and the final product was diluted 6 times in RNAse-free water. For RNA of sorted cells, cDNA was pre-amplified (TaqMan ${ }^{\circledR}$ Pre Amp Master Mix (2×) \#4384266) with a pool of TaqMan probes, and the final pre-amplified product was diluted 20 times with tris-EDTA (TE) buffer $\mathrm{pH} 8.0$ (\#BP2473, Fisher Bioreagents). Quantitative real-time RT-PCR analysis was carried out with Taqman system (\#4304437, Life Technology) using the iCycler iQTM Multicolor Real-Time Detection System (Bio-Rad, Hercules, CA, USA).

\section{RNA microarray and bioinformatics}

Six RNA samples obtained from sorted $\mathrm{CD} 11 \mathrm{~b}^{+} \mathrm{CD} 163^{+}$ cells (from three control rats and three ischemic rats at $16 \mathrm{~h}$ post-ischemia) with RIN values $>9.2$ were selected for RNA microarray study with GeneChip Rat Genome 230 2.0 Array, 3'IVT Pico reagent kit (Affymetrix). The images were processed with the Expression Console software (Affymetrix) to check the array quality. Genes selected as being differentially expressed were clustered to look for common patterns of expression. Bioinformatics analyses of functional and biological significance were carried out.

\section{Immunohistochemistry of paraffin embedded brain sections}

Rats were anesthetized with isoflurane and perfused through the heart with saline followed by $4 \%$ PFA. Careful extraction of the brain from the skull allowed keeping most of the pia meningeal layer attached to the brain tissue. The brain was kept in $4 \%$ PFA overnight at $4{ }^{\circ} \mathrm{C}$, washed in phosphate buffer and embedded in paraffin. Immunohistochemistry was carried out in $5 \mu$ m-thick paraffin section with the following primary antibodies: a mouse monoclonal antibody against CD163 (clone ED2, which recognizes the rat CD163 cell surface glycoprotein [7]) (\# MCA342GA, $0.5 \mathrm{mg} / \mathrm{mL}$, AbD Serotec, Bio-Rad) diluted 1:50, and rabbit polyclonal antibodies against Iba-1 (\# 019-19,741, $0.5 \mathrm{mg} /$ $\mathrm{mL}$, Wako Chemicals USA, Inc.) diluted 1:500, and against myeloperoxidase (MPO) (\# A0398, $3.3 \mathrm{mg} / \mathrm{mL}$, Dako), diluted 1:100, using the EnVisionTM Detection System; (\# K5007, Dako). Following incubation with biotinylated secondary antibodies (anti-rabbit made in goat \# BA-1000; and anti-mouse made in horse \# BA2001; both from VECTOR and used at 1:200 dilution), the immunoreaction was visualized with the avidin-biotin peroxidase method (ABC, Vector, Palex Medical S.A., Sant Cugat del Vallès, Spain) and diamenobenzidine. Cell counting was performed in a blinded fashion.

\section{Evans blue technique}

A solution of $2 \%$ Evans blue (Sigma-Aldrich) ( $w / v$ in saline) was administered i.v. ( $4 \mathrm{~mL} / \mathrm{kg}$ of body weight) $22 \mathrm{~h}$ after ischemia. Two hours later, rats were anesthetized and perfused with saline. We obtained images of $1-\mathrm{mm}$ thick coronal sections of fresh brain that were analysed with ImageJ software.

\section{Western blotting}

Proteins were separated by electrophoresis in $12 \%$ polyacrilamide gels and were transferred to polyvinylidene fluoride membranes (Immobilon-P, \# IPVH00010, MilliporeSigma) and incubated overnight at $4{ }^{\circ} \mathrm{C}$ with a goat polyclonal antibody anti-VEGF-A (\#AF564, R\&D) diluted 1:500, followed by a secondary anti-goat HRP antibody diluted 1:2000. $\beta$-tubulin was used as the loading control.

\section{Post-mortem tissue of stroke patients}

We studied the brain of three stroke patients (female; 63, 81 and 89 years old) deceased on day 1 after ischemic stroke onset. Two patients had right MCA infarcts and the third had a vertebro-basilar infarction, with a National Institute of Health Stroke Scale (NIHSS) severity score of 20,13 , and 9, respectively. Only the first of these patients received mechanical thrombectomy, whereas the other 


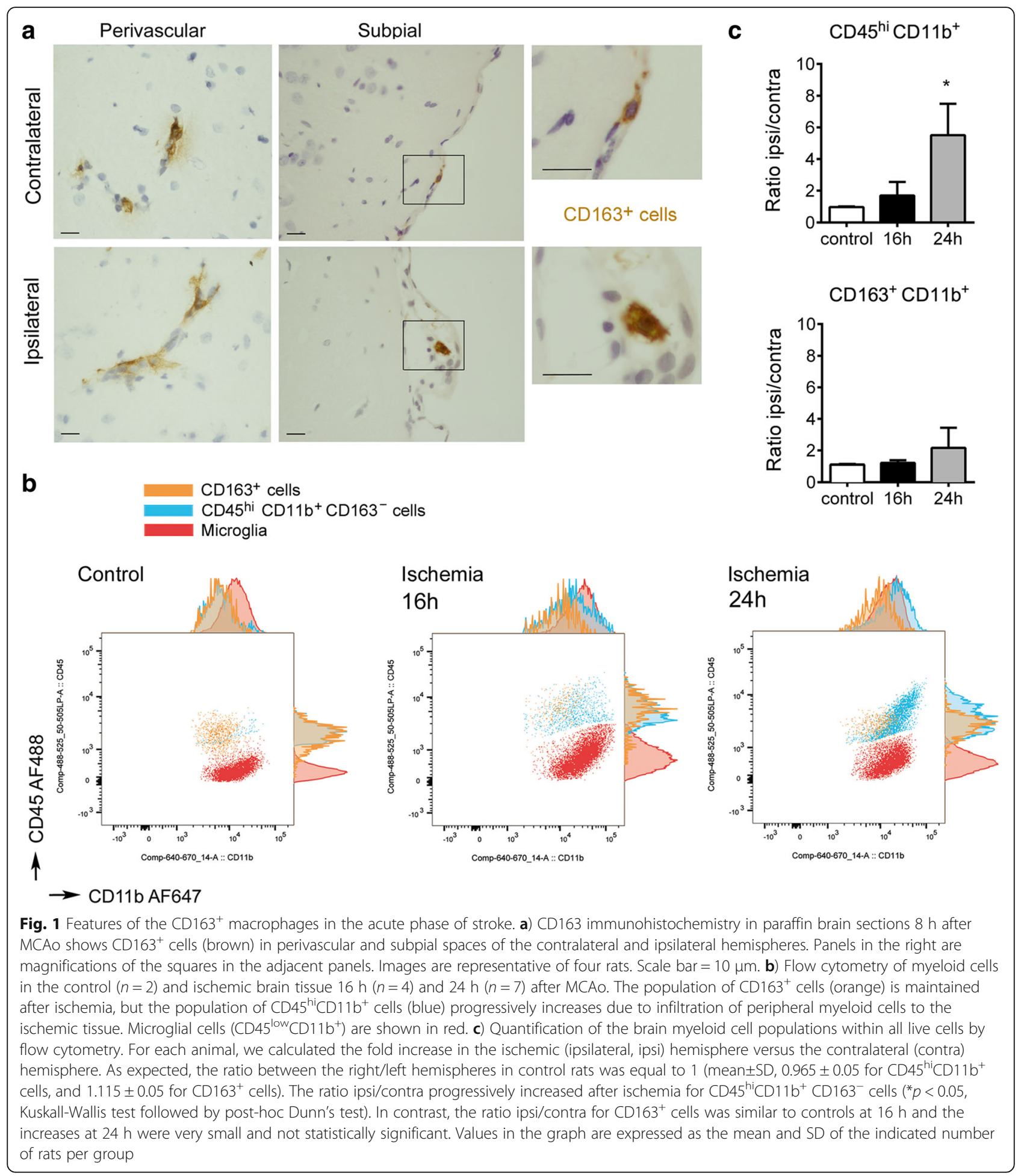

two patients did not receive any revascularization therapy. None of the patients received tPA. The mean \pm SD time lapse from exitus to necropsy was $4.3 \pm 3.2 \mathrm{~h}$. Expert neuropathologists obtained ischemic tissue that was embedded in optimal cutting temperature (OCT) compound and immediately frozen in liquid nitrogen for later sectioning in a cryostat at $5 \mu \mathrm{m}$. The sections were processed for immunofluorescence using the following primary antibodies: mouse monoclonal antibody anti-CD163 (clone EDHu-1, $1 \mathrm{mg} / \mathrm{mL}$, \# MCA1853, Serotec, Bio-Rad) diluted 1:200; rabbit polyclonal antibody anti-VEGFA $(0.9 \mathrm{mg} / \mathrm{mL}$, \# ab46154, Abcam) diluted 1:100; and sheep polyclonal 


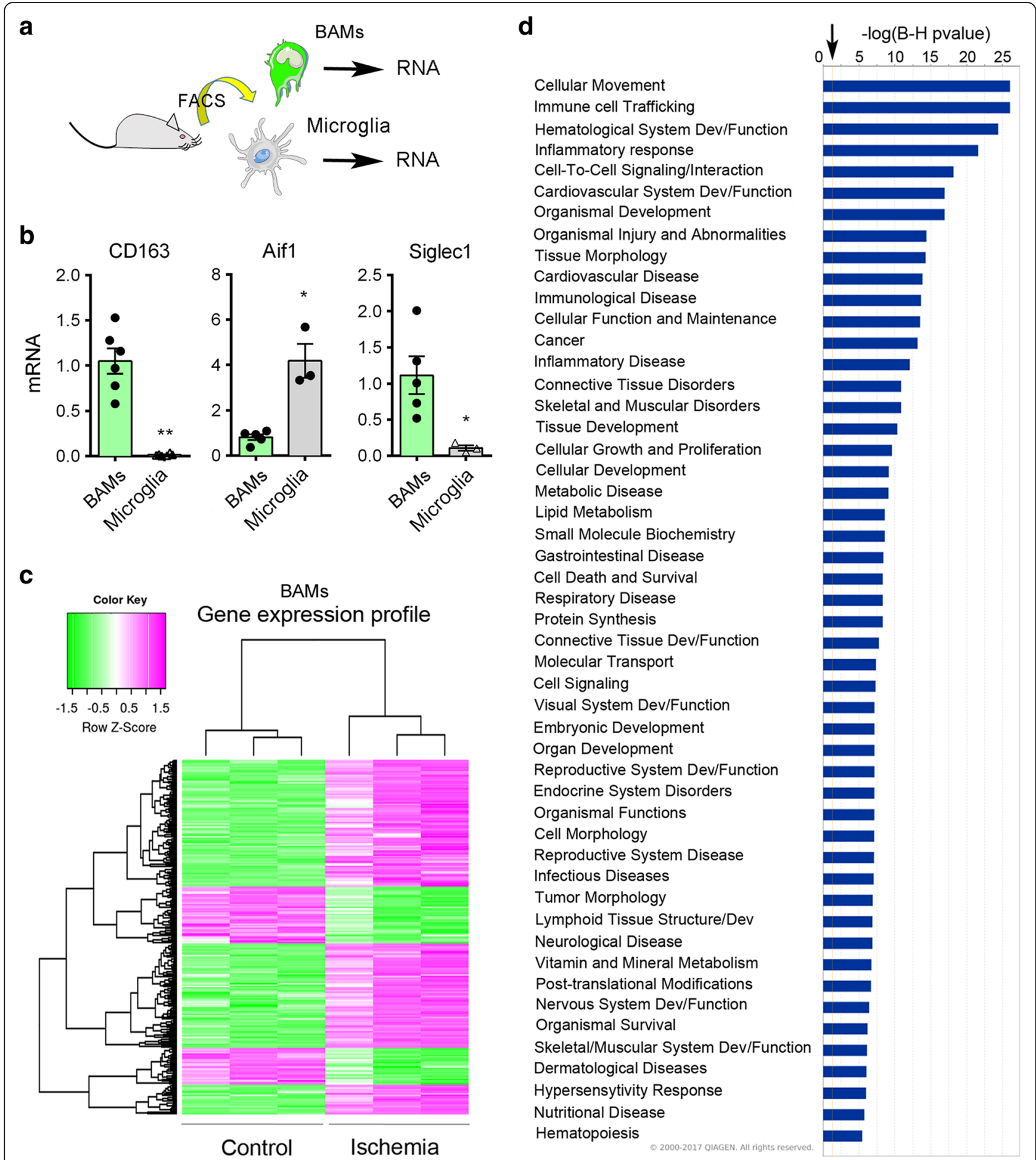

Fig. 2 (See legend on next page.) 


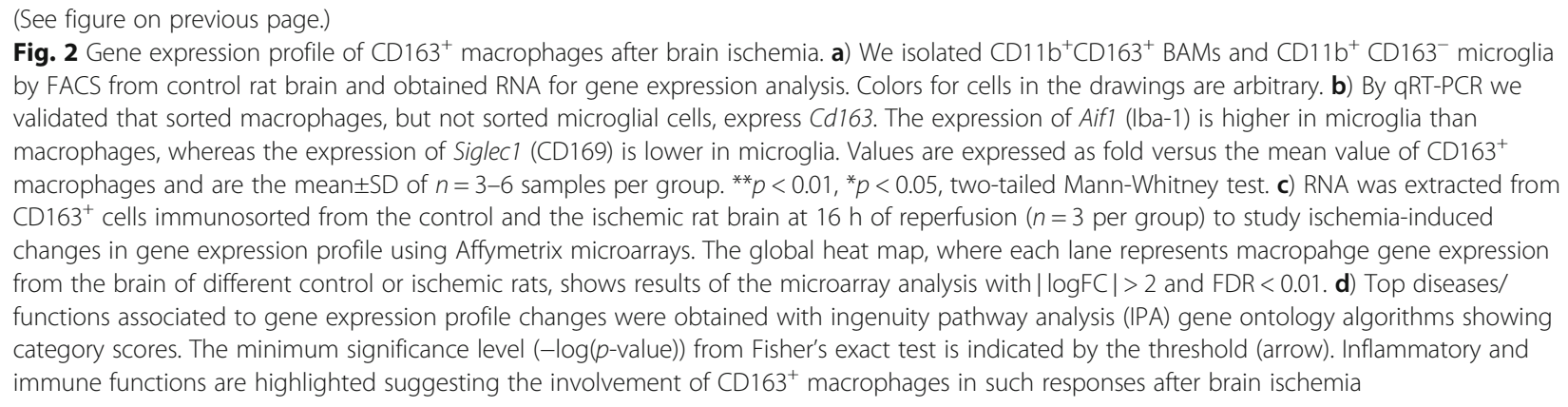

antibody anti-vWF (\# ab11713, $6.8 \mathrm{mg} / \mathrm{mL}$, Abcam) diluted 1:100. Sections were incubated overnight at $4{ }^{\circ} \mathrm{C}$ with primary antibodies followed by incubation for $2 \mathrm{~h}$ at room temperature with secondary antibodies (Life Technologies): Alexa Fluor-488 (\# A11017 anti-mouse made in goat, and \# A21206 anti-rabbit made in donkey), Alexa Fluor-546 (\# A10036 anti-mouse made in donkey, and \# A10040 anti-rabbit made in donkey) and Alexa Flour-647 (\# A21448 anti-sheep made in donkey), all diluted 1:500. $0.3 \%$ Sudan black in $70 \%$ ethanol was used to reduce tissue autofluorescence. Immunoreaction controls were carried out by omission of the primary antibodies, and by substituting the primary anti-VEGFA antibody by rabbit immunoglobulin fraction (\# 0903, $20 \mathrm{mg} / \mathrm{mL}$, Dako) diluted 1:2200. Sections were counterstained with 4',6-diamidino-2-phenylindole (DAPI) (Invitrogen) to visualize the cell nuclei and they were observed under a confocal laser microscope (Zeiss LSM 880). Confocal images were processed with ImageJ software to display the pictures.

\section{Statistical analyses}

Comparisons between two groups were carried out with two-tailed Mann-Whitney or unpaired Student t-test after testing for normal distribution using the Kolmogorov-Smirnov test. Multiple comparisons were carried out with the non-parametric Kruskal-Wallis test followed by post-hoc Dunn's test. Two-way ANOVA was used to compare group differences by treatment (clodronate vs. vehicle) and condition (ischemia vs. control). The Bonferroni's Multiple Comparison tests was used for post-hoc analysis. Statistical analyses were carried out with GraphPad Prism software. The sample size in experiments designed to investigate the effect of drug treatment on stroke outcome was $n=16$, as calculated using G*"power 3.1 software (Düsseldorf University) with an estimated effect size d of 0.9 , alpha level of 0.05 , and statistical power of 0.8 .

\section{Results}

Features of $\mathrm{CD}_{163^{+}}$cells in the control brain and in the acute phase of stroke

The $\mathrm{CD}_{163^{+}}$rat brain cells studied in this work include perivascular macrophages and subpial macrophages that remained attached to the glial limitans after removing the brain from the skull (Fig. 1a). Flow cytometry of control brain tissue showed a higher level of CD45 expression in $\mathrm{CD}_{163}{ }^{+}$macrophages than in microglia $\left(\mathrm{CD} 45^{\text {low }} \mathrm{CD} 11 \mathrm{~b}^{+}\right.$ cells) (Fig. 1b). Ischemia induces macrophage infiltration to the brain peaking after several days [17, 47, 49, 52, 53]. We examined the $\mathrm{CD}_{163}{ }^{+}$cells and the $\mathrm{CD} 45^{+} \mathrm{CD} 11 \mathrm{~b}^{+}$myeloid cells in the control brain tissue and the brain tissue at $16 \mathrm{~h}$ and $24 \mathrm{~h}$ post-ischemia. Following ischemia, the population of $\mathrm{CD} 45^{\mathrm{hi}} \mathrm{CD} 11 \mathrm{~b}^{+}$myeloid cells progressively increased. In contrast, the population of $\mathrm{CD}_{163}{ }^{+}$cells remained similar to controls at $16 \mathrm{~h}$ and showed a tendency to increase in the ipsilateral hemisphere at $24 \mathrm{~h}$ (Fig. 1b,c). These results showed that most peripheral myeloid cells infiltrating the brain tissue in the first hours post-ischemia did not express CD163.

\section{Ischemia-induced changes in the gene expression profile of $\mathrm{CD} 163^{+}$BAMs}

To characterize the general phenotype of $\mathrm{CD}_{163}{ }^{+}$macrophages and compare it with that of microglia, we isolated the $\mathrm{CD}_{163^{+}}$cells and the $\mathrm{CD} 163^{-}$microglia from the control rat brain by fluorescence-activated cell sorting (FACS) (Fig. 2a, see gates used for cell sorting in Additional file 1: Figure S1a). We checked the purity (mean $\pm \mathrm{SD}, \mathrm{n}$ rats) of the sorted cells by flow cytometry and found that $92.0 \pm 4.2 \%(n=4)$ of the sorted cells were $\mathrm{CD} 11 \mathrm{~b}^{+} \mathrm{CD} 163^{+}$cells. We also verified by flow cytometry that the $\mathrm{CD}_{11} \mathrm{~b}^{+} \mathrm{CD} 163^{-}$cell population was enriched in $\mathrm{CD} 45^{\mathrm{dim}} \mathrm{CD} 11 \mathrm{~b}^{+}$microglia $(92.9 \pm 2.4 \%, n=$ $2)$. We then performed additional cell sorting experiments for RNA extraction and gene expression studies (Fig. 2a). By qRT-PCR we detected Cd163 mRNA expression in the sorted $\mathrm{CD}_{163^{+}}$population but not in the sorted microglia, as expected, whereas the expression of Aif1 (Iba-1) was higher in microglia than in the $\mathrm{CD} 163^{+}$ cells, and Siglec1 (CD169) expression was detected in $\mathrm{CD}_{163}{ }^{+}$cells but not in microglia (Fig. $2 \mathrm{~b}$ ).

We aimed to investigate whether ischemia changed the gene expression profile of the resident $\mathrm{CD}_{163}{ }^{+}$macro-

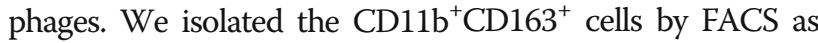
above in groups of control non-ischemic rats and rats 







\section{a}
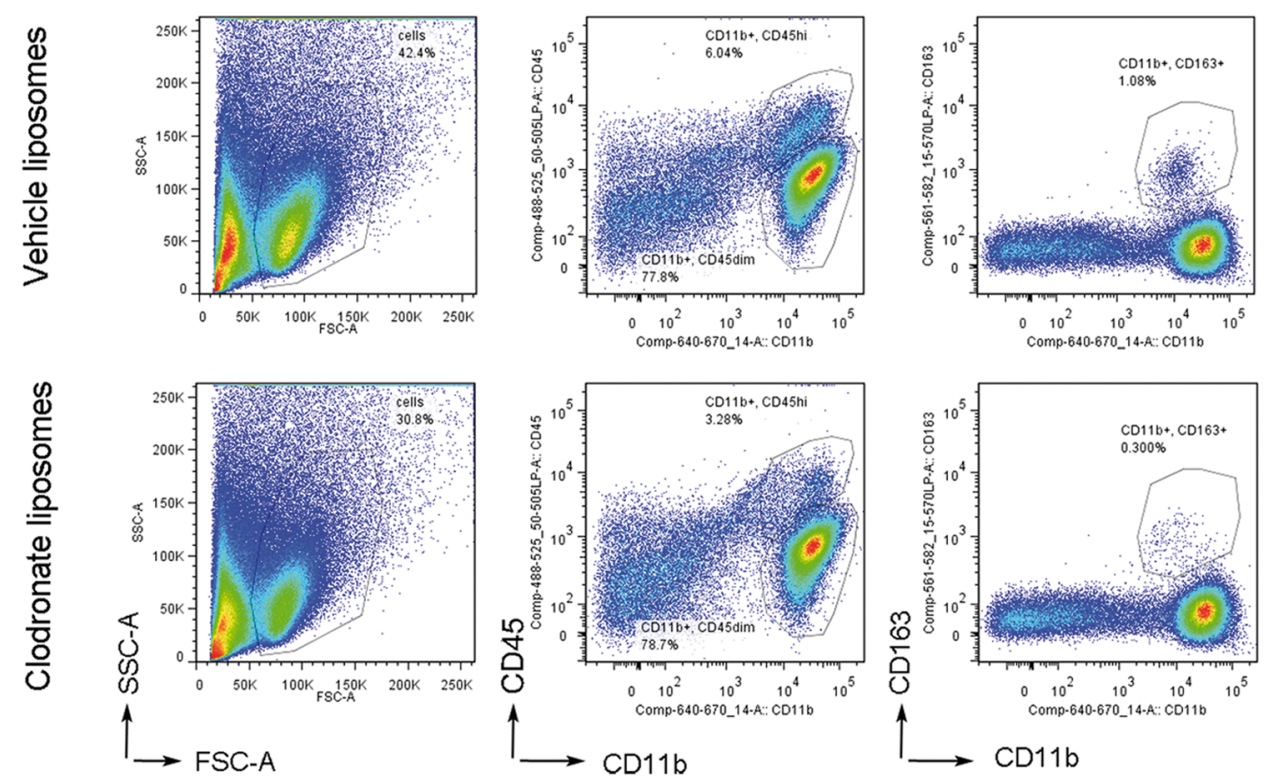

b

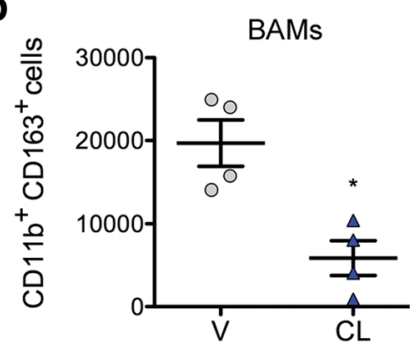

C

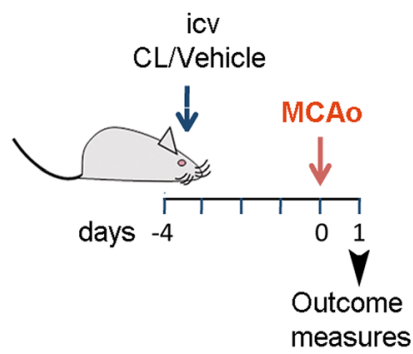

d

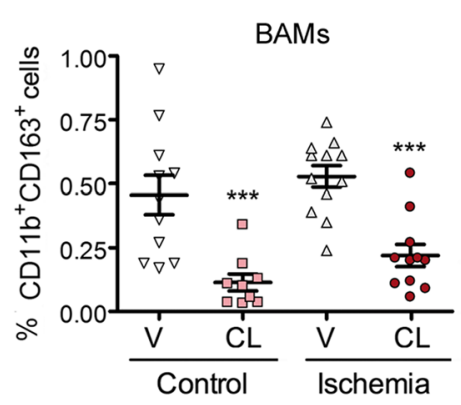

e

Contralateral hemisphere

CD163

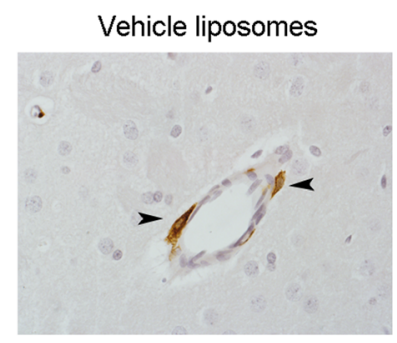

Clodronate liposomes
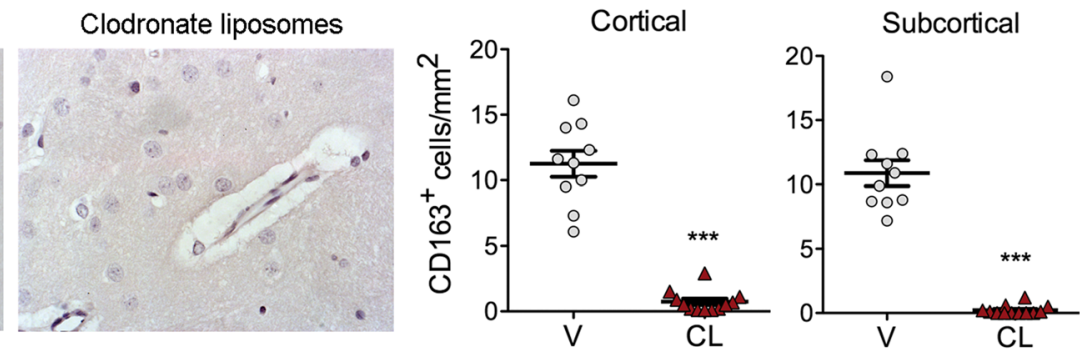

Ipsilateral hemisphere

Vehicle liposomes

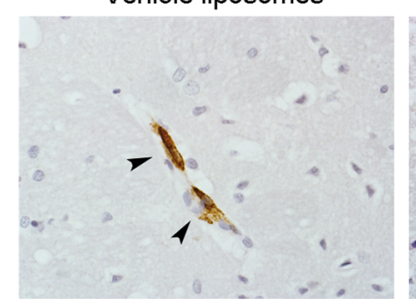

clodron

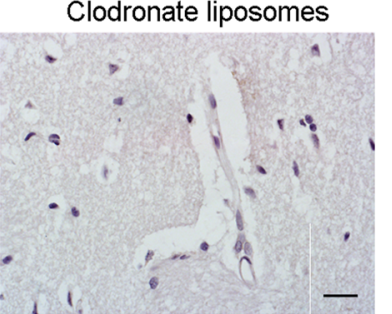

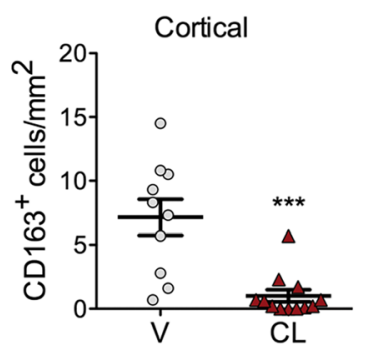

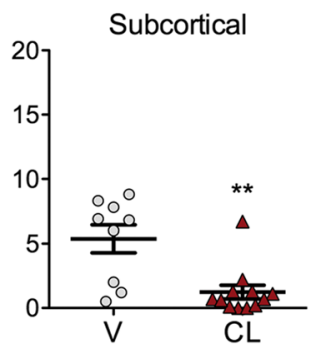

Fig. 4 (See legend on next page.) 


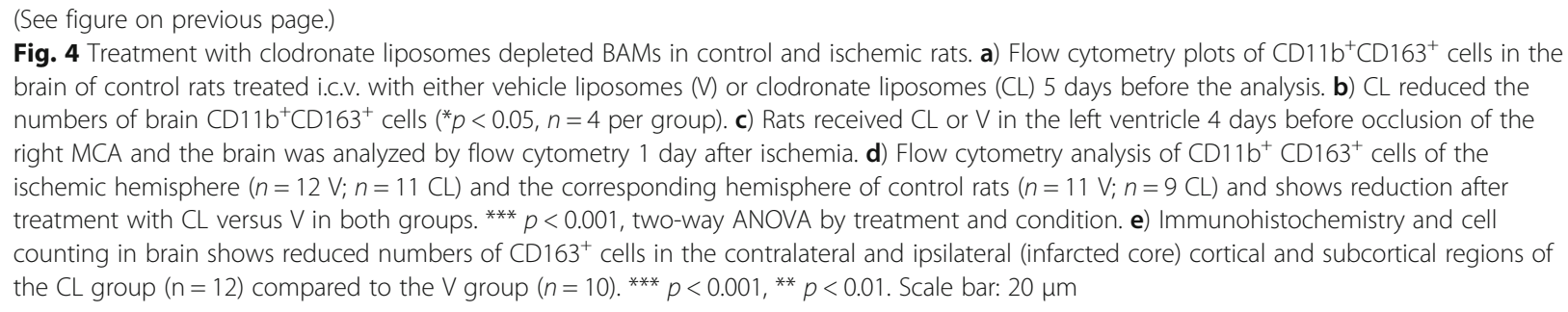

subjected to ischemia plus $16 \mathrm{~h}$ of reperfusion (Additional file 1: Figure $\mathrm{S} 1 \mathrm{~b}$ ). We chose to study this time point after ischemia given that myeloid cell infiltration was still very mild and the majority of $\mathrm{CD} 163^{+}$cells were resident macrophages (Fig. 1b,c). We obtained RNA from the sorted cells, and processed it with Affymetrix microarrays. Unsupervised clustering analysis showed that the samples clustered according to the groups (Additional file 1: Figure S2a), and principal component analysis precisely separated the ischemic from the control samples (Additional file 1: Figure S2b). We selected the genes showing statistically significant differences between ischemic and control groups (adjusted $p$-value $<0.01)$ and filtered for $|\log \mathrm{FC}|>2$. According to the above criteria, the expression of 1493 genes was up-regulated whereas the expression of 594 genes was down-regulated in $\mathrm{CD}_{163}{ }^{+}$macrophages after ischemia, as graphically illustrated in the volcano plot (Additional file 1: Figure S2c). The global heat map illustrates differentially expressed genes in these groups (Fig. 2c). The top 25 up-regulated genes (Additional file 1: Table S1) included genes related to the extracellular matrix, such as Vcan (versican), Sdc1 (syndecan), Fn1 (fibronectin-1), Spp1 (osteopontin), Sema3c (semaphorin 3c), Mmp7 (matrix metalloproteinase 7, MMP-7), and Mmp14 (MMP-14) supporting a role of $\mathrm{CD} 163^{+}$macrophages in extracellular matrix remodelling. Also, we detected up-regulation of genes involved in nicotinamide adenine dinucleotide metabolism (Cd38), and inflammatory and immune responses, like Tspo, Cd8a, and Itgax (CD11c). The sorted CD163 ${ }^{+}$ cells expressed genes recently identified in BAMs of the mouse brain, such as Mrc1 (CD206), Mertk, Adgre1 (F4.80), Fcgr3a (CD16), C5ar1 (CD88), Lyve1, RT1-ba (MHC class II antigen), Cd44, Cd38 [37], and Tmem119, Csf1r, and Cxcr4 [29]. However, the expression of most of these genes did not significantly change after ischemia, with the exception of increased expression of $C d 38$ (Additional file 1: Figure S3A) and $C d 44$ (Fig. 3b). Neither control nor ischemic $\mathrm{CD}_{163}{ }^{+}$BAMs showed expression of genes encoding for typical microglial proteins, like Sall1. Among the top genes down-regulated after ischemia we found the $\alpha$-amino-3-hydroxy-5-methyl-4-isoxazolepropionic acid (AMPA) glutamate receptor Gria2, genes related to subcellular organization, like Syne 2 and Fam65b, and genes of the extracellular matrix, such as Adam23, certain growth factor receptors, like Egfr, and genes related to immune responses particularly associated to inhibition of leukocyte activation, such as Siglec5 (Additional file 1: Table S2).

The analysis of biological significance was based on enrichment analysis on different annotation databases to highlight biological categories in which the selected genes appear to be over-represented after brain ischemia. The GO analysis identified over-representation, enriched KEGG entities and clusters for terms related to acute inflammatory response, cytokine activity, chemokine activity, response to hypoxia, extracellular space, extracellular matrix, metalloproteinases, collagen degradation, blood vessel remodelling, angiogenesis, and response to oxidative stress, amongst others (see Additional file 1: Figure S3 for heat maps of genes in GO-terms representative of the inflammatory response). Down-regulated KEGG pathways included: ATPase, $\mathrm{Ca}^{++}$transporting; ATPase, $\mathrm{Na}^{+} / \mathrm{K}^{+}$ transporting; Cd7 molecule; KIT ligand; beta-2-adrenergic receptor; and epidermal growth factor receptor (Egfr) pathway. Ingenuity Pathway Analysis (IPA) identified top canonical pathways (Additional file 1: Figure S4A) and top associated disease/functions (Fig. 2d). Amongst the highly up-regulated pathways, hypoxia inducible factor-1 (HIF-1) signalling highlighted the response to ischemic conditions (Additional file 1: Figure S4), illustrated by up-regulation of Hifla and vascular endothelial growth factor-A (Vegfa) genes (Fig. 3a, Additional file 1: Figure S3). The term lipopolysaccharide (LPS) was amongst the top upstream regulators, suggesting acquisition of pro-inflammatory features reminiscent of the response to LPS. However, ischemia-induced $\mathrm{CD}_{163^{+}}$macrophage activation showed a distinctive metabolic and inflammatory signature. For instance, regarding arginine metabolism [38], inducible nitric oxide synthase (iNOS, Nos2) was not overrepresented whereas arginase-1 (Arg1) was one of the top up-regulated genes (Additional file 1: Table S1). This effect is expected to suppress excessive nitric oxide production and promote L-arginine consumption impairing lymphocyte activation in response to antigen $[3,8]$.

\section{Ischemia induces the expression of leukocyte chemoattractants in $\mathrm{CD} 163^{+}$BAMs}

The above gene pathway analyses in $\mathrm{CD} 163^{+}$macrophages highlighted the response to wounding, inflammation, and 
chemotaxis after ischemia. A heatmap representation is shown for the GO term Leukocyte chemotaxis where several genes up-regulated by ischemia are detailed (Fig. 3a). The IPA analysis identified over-representation of the term Neutrophil recruitment (Fig. 3b). The analyses showed up-regulation of genes such as Spp1, interleukin-6 (Il6), C-X-C motif chemokine ligands 14 (Cxcl14), S1008a, and L-selectin (Sell), amongst others. Ischemia also up-regulated genes encoding for chemokines involved in recruiting $\mathrm{T}$ helper type 2 (Th2) lymphocytes, like $\mathrm{Ccl} 22$ and Ccl17 [56] (Fig. 3, Additional file 1: Table S1). For validation purposes, some of the up-regulated genes related to leukocyte chemotaxis were studied by qRT-PCR using RNA of $\mathrm{CD}_{163}{ }^{+}$macrophages sorted from different groups of control and ischemic rats $16 \mathrm{~h}$ post-ischemia (Fig. 3c). We compared the expression of these genes in FACS-sorted $\mathrm{CD} 11 \mathrm{~b}^{+} \mathrm{CD}_{163}{ }^{+}$cells versus sorted

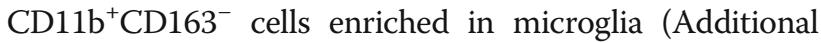
file 1: Figure S1). $\mathrm{CD}_{163^{+}}$macrophages seemed to work in consonance with microglia to promote leukocyte recruitment to the ischemic brain since most of the genes that we studied by qRT-PCR showed similar (e.g Spp1, C1qbp) or weaker (e.g. Sell) expression in $\mathrm{CD}_{163}{ }^{+}$macrophages compared to microglia. However, ischemia up-regulated certain genes, such as Ccl17, preferentially in $\mathrm{CD}_{163}{ }^{+}$macrophages (Fig. $3 d)$. Altogether, these results suggested the possibility that $\mathrm{CD}_{163^{+}}$macrophages participated in the recruitment of leukocytes after brain ischemia.
Selective depletion of BAMs but not microglia in control and ischemic brain

To obtain functional information on the role of BAMs in the acute phase of stroke, we carried out loss-of-function experiments by intracerebroventricular (i.c.v.) administration of liposomes containing clodronate [14, 23, 42, 43]. Macrophages scavenge the liposomes and the intracellular accumulation of the toxin clodronate induces macrophage cell death $[46,55]$. Liposomes containing either clodronate or vehicle (PBS) were administered in the left ventricle and the brain was analyzed 5 days later. Flow cytometry studies of the brain cells showed that clodronate liposomes induced a strong reduction $(65-70 \%)$ of the $\mathrm{CD} 163^{+}$population in both hemispheres (Fig. 4a,b). We then checked that CD163 ${ }^{+}$ cell depletion was maintained after brain ischemia. We occluded the right MCA four days after administration of clodronate or vehicle liposomes to the left ventricle and studied the brain tissue $24 \mathrm{~h}$ post-ischemia (Fig. 4c). $\mathrm{CD}_{163}{ }^{+}$cells were also reduced in the ischemic tissue after clodronate treatment, as assessed by flow cytometry (Fig. 4d). Immunohistochemistry (Fig. 4e) showed depletion of $\mathrm{CD}_{163}{ }^{+}$macrophages located in the perivascular spaces and on the glia limitans under the pia matter. Of note, we verified that i.c.v. clodronate liposome treatment did not significantly affect the number of parenchymal microglia compared to the vehicle group in the control and ischemic brain tissue, as shown by immunohistochemistry $\left(\mathrm{Iba}^{+}\right)$ (Additional file 1: Figure S5a), and flow cytometry $\left(\mathrm{CD} 45^{\mathrm{dim}} \mathrm{CD} 11 \mathrm{~b}^{+}\right)$(Additional file 1: Figure S5b). In both

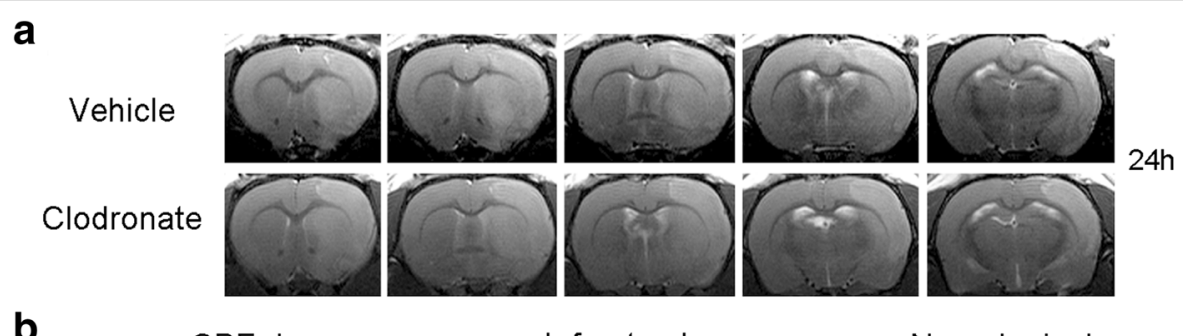

b

CBF drop

Infarct volume

Neurological score
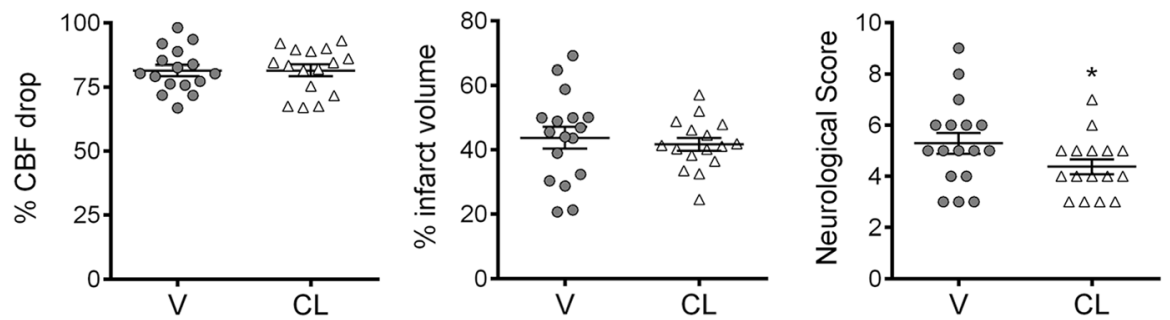

Fig. 5 Depletion of BAMs does not reduce infarct volume but attenuates the neurological deficit. a T2w MRI $24 \mathrm{~h}$ post-ischemia of representative rats per treatment group, i.e. clodronate $(\mathrm{CL}, n=16)$ or vehicle $(\mathrm{V}, n=17)$ liposomes. $\mathbf{b}$ Ischemia induced a similar drop of cortical perfusion (CBF) during MCAo, as assessed by laser Doppler, in both groups. The neurological score shows a small but significant improvement in the CL group. (Mann-Whitney test, ${ }^{*} p=0.046$ ) There are no differences between groups in total infarct volume (b), as well as the volume of infarcted cortical and subcortical regions (not shown), as assessed by T2w MRI. Treatment, ischemia, neurological evaluation, MRI, and infarct volume measures were carried out in a blinded fashion 


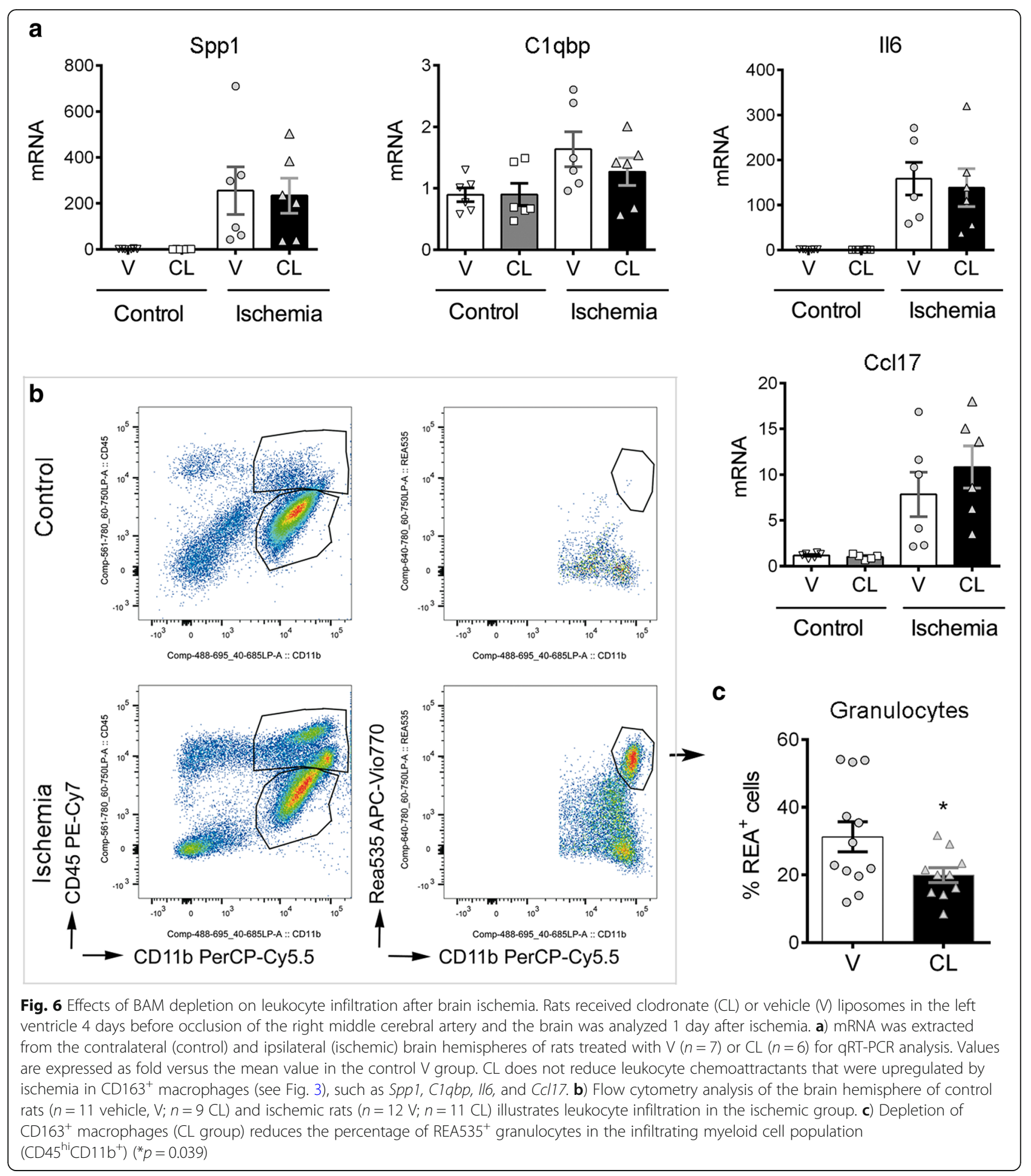

hemispheres of the clodronate group we observed the presence of $\mathrm{CD}_{163}{ }^{-} \mathrm{Iba1}^{+}$perivascular cells (Fig. 4e, Additional file 1: Figure S5b) that might correspond to peripheral myeloid cells. The effect of i.c.v. administration of clodronate was local and it did not modify blood cell counts (Additional file 1: Figure S6).
BAM depletion ameliorated the stroke-induced neurological dysfunction

To find out whether BAM depletion affected the extent of brain damage we measured the size of the brain lesion and assessed the neurological function $24 \mathrm{~h}$ post-ischemia in rats treated with clodronate or vehicle liposomes, as 


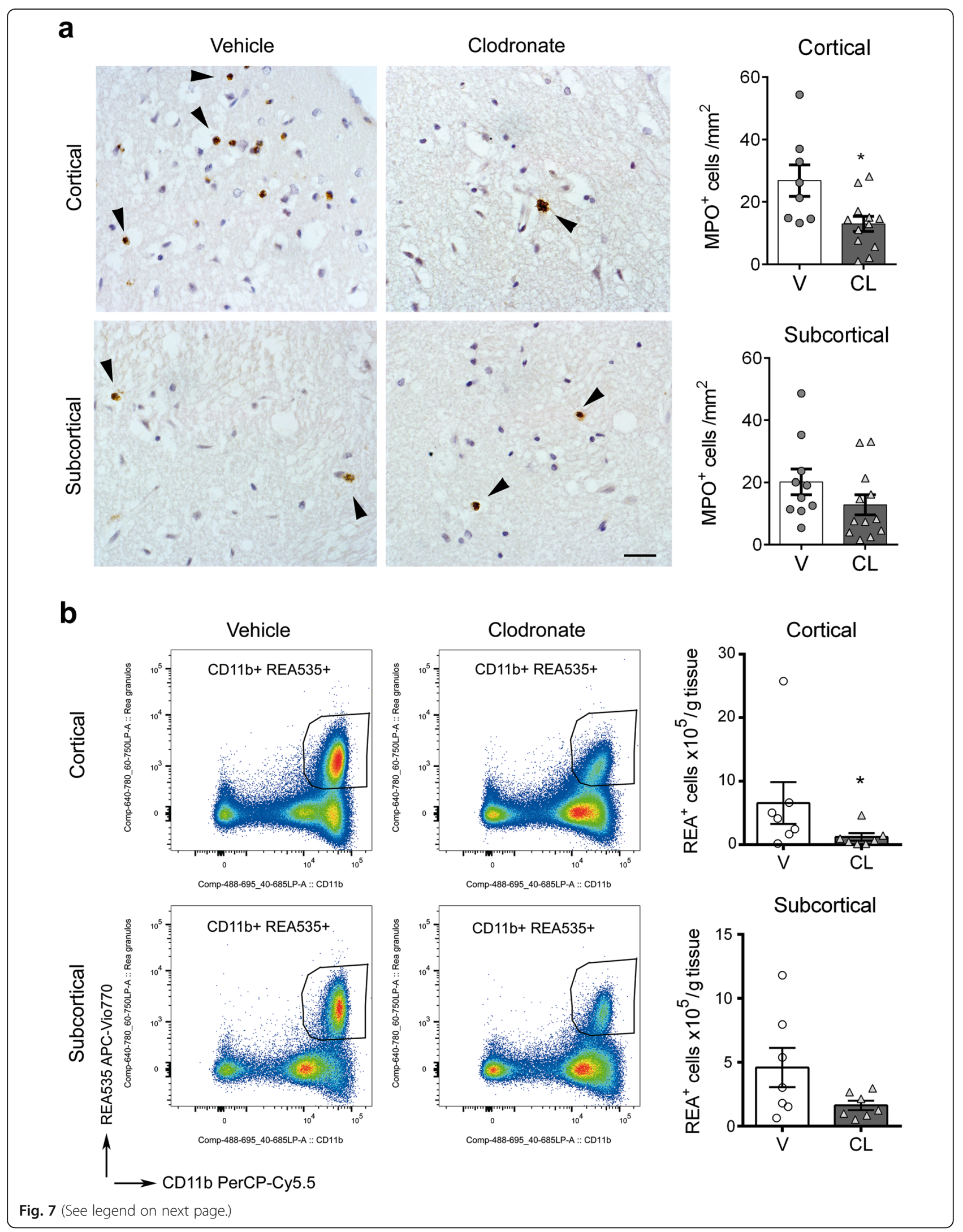


(See figure on previous page.)

Fig. 7 Depletion of BAMs reduces granulocyte infiltration in the ischemic cortex. Rats received clodronate (CL) or vehicle (V) liposomes in the left ventricle 4 days before occlusion of the right middle cerebral artery and the brain was analyzed 1 day after ischemia. a) Myeloperoxidase (MPO) immunohistochemistry (brown, arrows) of the core of infarction in paraffin sections (counterstained with hematoxylin in blue) of ischemic rats treated with $\mathrm{V}$ or $\mathrm{CL}$. Scale bar: $20 \mu \mathrm{m}$. Blind cell counting showed that $\mathrm{CL}(n=12)$ reduces the numbers of $\mathrm{MPO}^{+}$cells in the ischemic cortex compared to the $\mathrm{V}(n=8)\left({ }^{*} p=0.05\right)$, but differences in subcortical regions were not statistically significant $(\mathrm{CL} n=12, \mathrm{~V} n=10, p=0.12)$. b) An independent group of rats treated with $\mathrm{V}$ or $\mathrm{CL}$ was studied by flow cytometry $24 \mathrm{~h}$ postischemia after dissection of cortical and subcortical brain regions. The numbers of REA535 $5^{+}$granulocytes was determined. Values are expressed as number of cells per gram of brain tissue. The number of REA535 $5^{+}$cells decreased in both regions after BAM depletion. However, differences between treatment groups were statistically significant in cortical regions ( $\left.{ }^{*} p=0.038\right)$, whereas only a trend was observed in subcortical regions $(p=0.085)$

above. One-hour ischemia induced large brain lesions and BAM depletion did not cause a major effect in the volume of infarction (Fig. 5). However, rats depleted of BAMs showed a mild but significant improvement of the neurological score (Fig. 5), suggesting that BAM activity has negative consequences for the neurological status in the acute phase of stroke.

\section{BAM depletion alters leukocyte recruitment after brain ischemia}

We then investigated by qRT-PCR whether depletion of BAMs altered the RNA expression of cytokines and chemokines in the brain tissue $24 \mathrm{~h}$ after ischemia. The brain of rats treated with clodronate liposomes did not show a significant reduction in the mRNA expression of the leukocyte chemoattractants and chemokines that we examined (Fig. 6a). This result is compatible with ischemia-induced expression of these genes in other cells in addition to $\mathrm{CD} 163^{+}$macrophages, including microglia and potentially astrocytes or other neural cells. In spite of this, depletion of $\mathrm{CD}_{163}{ }^{+}$cells reduced the percentage of infiltrating REA $535^{+}$granulocytes in the ischemic hemisphere, as determined by flow cytometry (Fig. 6b,c) whereas the numbers of other leukocytes were not affected (Additional file 1: Figure S7). To validate this finding, we carried out immunohistochemistry with anti-myeloperoxidase antibodies in an independent group of rats. Blind cell counting showed less infiltrating granulocytes after BAM depletion, particularly in cortical regions (Fig. 7a). To further investigate possible regional differences we carried out a second flow cytometry study in an independent group of ischemic rats where we dissected out cortical and subcortical regions and analysed them separately. BAM depletion reduced REA535 granulocyte numbers in the ischemic cortex, whereas subcortical regions only showed a non-significant trend (Fig. 7b). In contrast to the effect on granulocyte recruitment, BAM depletion did not significantly modify the numbers of $\mathrm{T}$ cells, NK cells, or myeloid mononuclear cells infiltrating the ischemic tissue (Additional file 1: Figure S8).

\section{BAMs increase cortical vascular permeability $24 \mathrm{~h}$ after ischemia}

The microarray analysis of sorted $\mathrm{CD} 163^{+}$macrophages identified over-representation of genes involved in the post-ischemic response to hypoxia, such as the HIF-target gene Vegfa (Fig. 3a, Additional file 1: Figure S3a). BAM depletion reduced the expression of Vegfa mRNA in the cerebral cortex $24 \mathrm{~h}$ post-ischemia, whereas this effect was milder in subcortical regions (Fig. 8a). Ischemia induced the expression of $\mathrm{VEGF}_{164}$ protein (Fig. 8b), a VEGF-A isoform (similar to human $\mathrm{VEGF}_{165}$ ) that is secreted and has the capacity to bind to the extracellular matrix [45]. In agreement with the mRNA results, BAM depletion reduced the cortical expression of $\mathrm{VEGF}_{164}$ (Fig. 8b).

Given that hypoxia-induced VEGF in the brain produces acute vascular leakage [48], we studied whether BAM depletion affected vascular permeability. Notably, ischemia-induced Evans blue extravasation from the ipsilateral pial vessels and cortex was minimal in rats depleted of BAMs (Fig. 8c), which showed a reduced volume of tissue with Evans blue extravasation in the cortex but not in subcortical regions. These results suggest that depletion of BAMs prevented ischemia-induced leakage of pial and cortical vessels.

We then investigated whether these findings might be relevant to acute ischemic stroke in humans. To this end, we studied $\mathrm{CD}_{163}{ }^{+}$macrophages in post-mortem brain tissue of three patients with fatal ischemic stroke deceased $24 \mathrm{~h}$ after symptom onset. VEGF immunoreaction was detected surrounding blood vessels and we found some $\mathrm{CD} 163^{+}$perivascular macrophages positive for VEGF (Fig. 9). We observed that VEGF immunoreactivity was more prominent in the two patients that did not receive any revascularization therapy than in the patient that received mechanical thrombectomy. This effect is likely attributable to persistent ischemic conditions in the former. The described perivascular VEGF immunoreaction was mainly found at the periphery of the infarcted core. In the infarcted core, we also observed VEGF immunoreactivity in parenchymal $\mathrm{CD} 163^{-}$cells with a pattern of expression that varied across the tissue and between patients. Altogether, these results are compatible with the possibility that human $\mathrm{CD} 163^{+}$ perivascular macrophages secreted VEGF in acute ischemic stroke. 


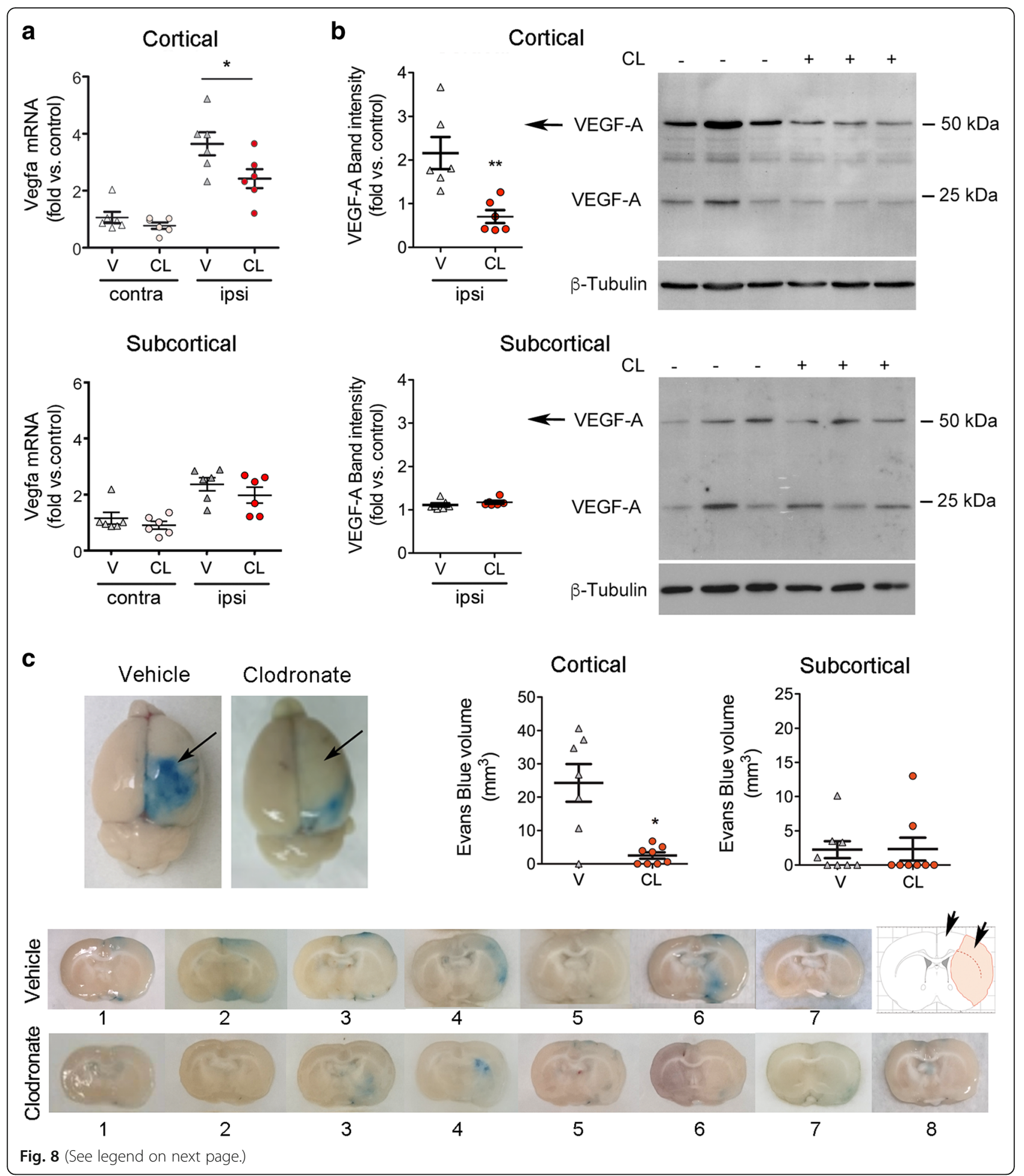




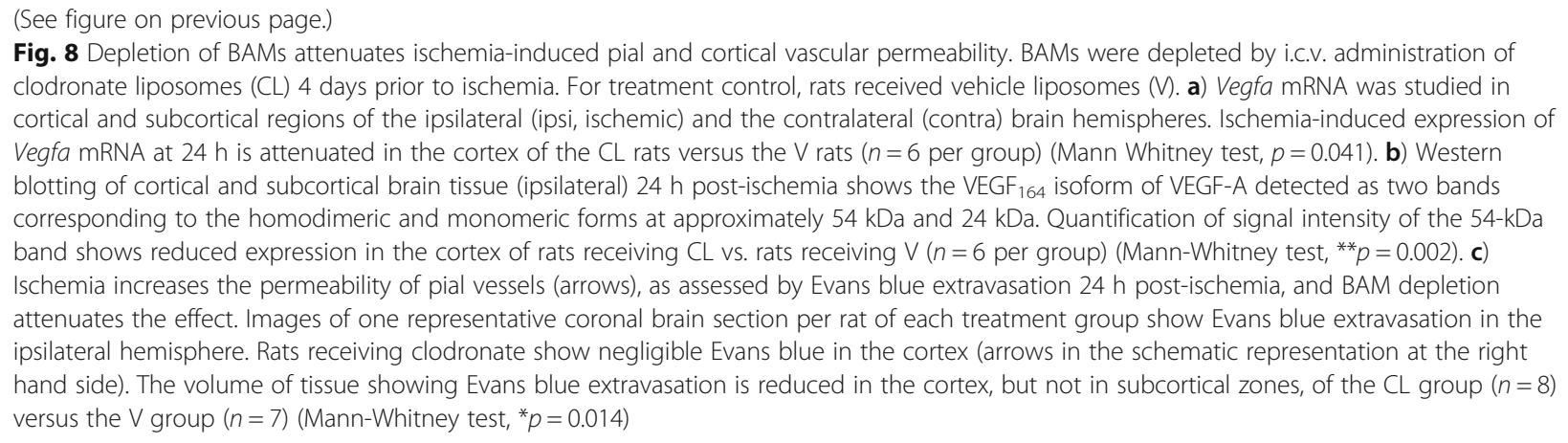

\section{Discussion}

BAMs are players at the interface between the nervous system and the immune system [6, 12, 27, 29, 34, 37, 53]. However, the precise functions of these cells under pathological conditions remain largely unknown. This study provides evidence for a role of BAMs increasing vascular permeability, facilitating granulocyte recruitment, and contributing to neurological dysfunction in the acute phase of ischemic stroke. BAMs express typical myeloid cell markers like microglia but their differential phenotypic features were less known until recently published studies provided an extensive description of the phenotype of BAMs in the mouse brain $[29,37]$. We verified that rat $\mathrm{CD} 163^{+}$BAMs expressed genes encoding for proteins identified in these latter works. However, the expression of most of these BAM genes did not significantly change $16 \mathrm{~h}$ post-ischemia versus controls, with the exception of increased expression of $C d 38$ and Cd44. Although CD44 expression was previously considered as a marker of brain infiltrating cells [29], we detected the expression of $\mathrm{Cd} 44$ in $\mathrm{CD}_{163}{ }^{+}$BAMs obtained from the control rat brain, in agreement with the finding of $\mathrm{CD} 44^{+}$BAMs in the control mouse brain [37]. Furthermore, the expression of Cd44 increased after ischemia, as described for CD44 expression in mouse BAMs in EAE [37]. In addition, we found that rat $\mathrm{CD}_{163}{ }^{+}$BAMs express Siglec1 (CD169) and low levels of Aif1 (Iba-1), in contrast to microglial cells that do not express Siglec1 and express comparatively higher levels of Aif1.

Brain ischemia causes necrotic neuronal cell death with release of danger signals that activate the microglia [26], but the response of BAMs is currently unknown. We found that these cells respond to ischemic conditions by showing changes in the gene expression profile enabling adaptation to hypoxia and acquisition of novel cellular functions involved in extracellular matrix-vascular interactions and inflammatory responses. BAMs upregulated the expression of genes regulating neutrophil chemotaxis as part of the reprogramming process induced by ischemia. The anatomic location of these cells confers them the capacity to participate in the communication network between the brain environment and the vasculature. Brain ischemia induces neutrophil extravasation from leptomeningeal vessels and neutrophil accumulation in perivascular spaces of the affected brain region $[9,40]$. Our study suggests that $C D 163^{+}$ macrophages attract granulocytes to the leptomeningeal and perivascular spaces in response to brain ischemia. These findings are in consonance with a study showing that perivascular macrophage depletion reduced brain neutrophil infiltration in a model of vesicular stomatitis viral infection [51]. Furthermore, perivascular macrophages mediate neutrophil recruitment during bacterial skin infection [1]. Other works reported the involvement of mononuclear cells in neutrophil attraction. For instance, specific subsets of monocytes are key regulators of neutrophil extravasation in the lung [30].

Functional analysis of genes over-represented in $\mathrm{CD}_{163}{ }^{+}$BAMs after brain ischemia versus controls highlighted the activation of neovascularization processes and the HIF-1 pathway. This finding is consistent with the observed up-regulation of the HIF- $1 \alpha$ target gene Vegfa, a potent modulator of angiogenesis [2, 32] and regulator of the cellular redox status [11]. We observed the expression of VEGF in the post-mortem human brain tissue of stroke patients deceased $24 \mathrm{~h}$ after stroke onset, and detected VEGF surrounding some brain vessels and $\mathrm{CD}_{163}{ }^{+}$perivascular macrophages, suggesting that the findings in rats might be valid in acute ischemic stroke patients. Acute production of VEGF is associated with increases in vascular permeability [48]. In our study, BAM depletion in the rats decreased the ischemia-induced expression of Vegfa mRNA and the secreted protein isoform, $\mathrm{VEGF}_{164}$, in the cerebral cortex. Furthermore, BAM depletion reduced Evans blue extravasation from pial and cortical vessels, whereas these effects were less marked in subcortical regions. We argue that the greater cortical effect might be due to the activity of subpial macrophages increasing the permeability of pial vessels in the acute 


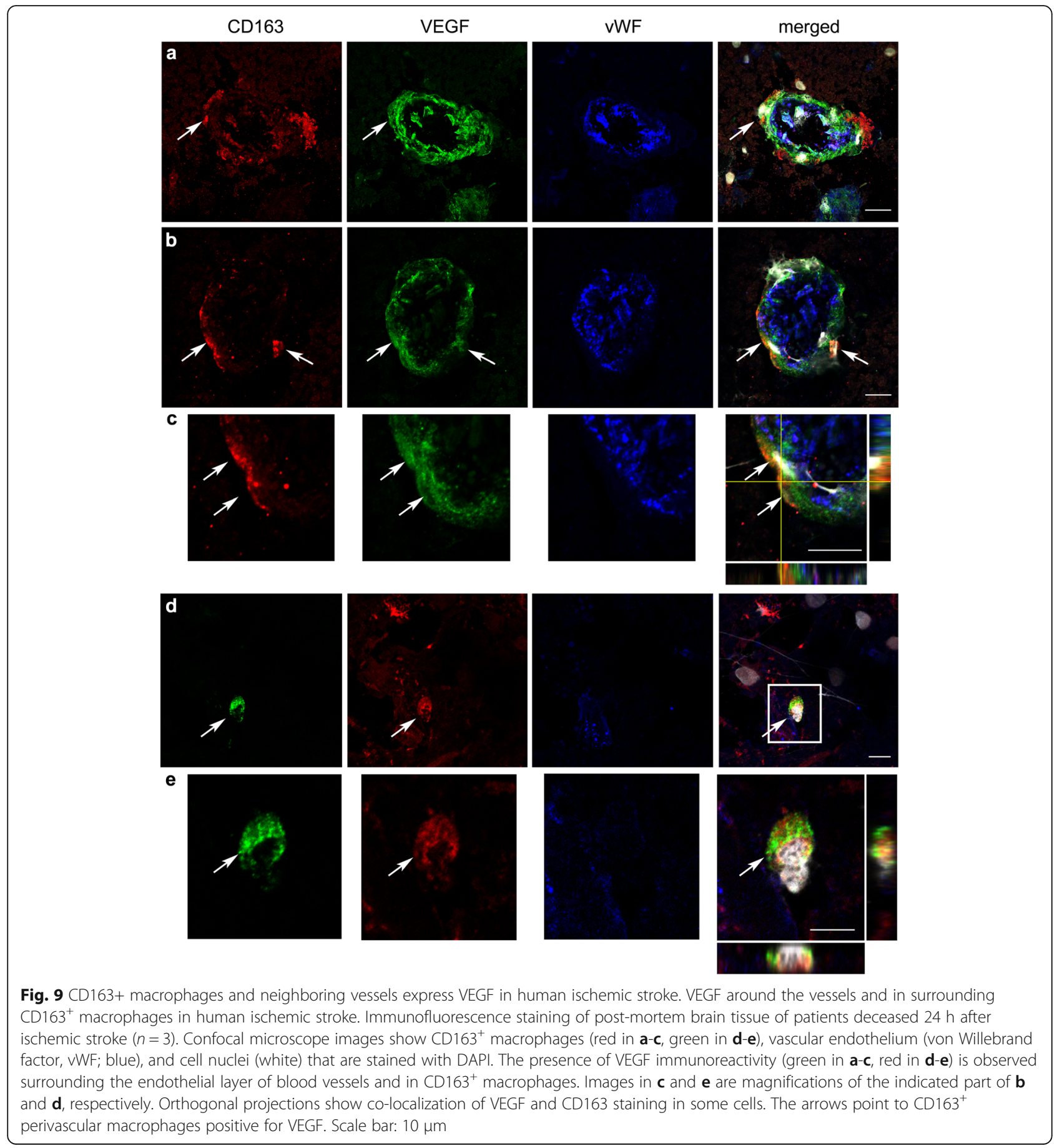

phase of stroke. While we were preparing this manuscript, a study reported pathogenic actions of $\mathrm{CD} 163^{+}$ macrophages in atherosclerosis where these cells showed activation of HIF1 $\alpha$ and VEGF expression and increased vascular permeability and inflammatory cell recruitment [20]. Interestingly, perivascular macrophages are involved in maintaining vascular barrier function in the periphery under physiological conditions [21, 24]. Here we show that an ischemic stroke challenge changes the homeostatic function of $\mathrm{CD} 163^{+}$macrophages by inducing cellular activation of the HIF pathway and generation of VEGF and inflammatory mediators. This effect in the very acute phase of stroke does not exclude putative vasculoprotective effects of perivascular macrophages in chronic phases after stroke.

Our study did not find any differences in infarct volume $24 \mathrm{~h}$ post-ischemia in rats depleted of BAMs, in spite that they showed reduced granulocytes in the ischemic brain. Previous studies reported reduced infarct 
volume after ischemia/reperfusion in rats depleted of neutrophils [35]. However, the effects were not entirely reproduced in a model of severe ischemia/reperfusion in rats [22], or in a model of ischemia/reperfusion plus thrombolytic treatment in spontaneous hypertensive rats where only one out of two different neutrophil depletion strategies reduced the lesion size [16]. Also, neutrophil depletion reduced infarct size in hyperlipidemic $\mathrm{ApoE}^{-/-}$ mice but not in normolipidemic wild-type mice [25]. Therefore, it was unlikely that the moderate reduction of granulocyte recruitment induced by BAM depletion in our model of severe ischemia/reperfusion was sufficient to cause major differences in the size of the severe brain lesion induced by our ischemia model. Nevertheless, we found some improvement of the neurological function in the absence of BAMs that was attributable to attenuated granulocyte recruitment and preservation of pial and cortical vascular integrity after ischemia.

A limitation of our study is that it only addressed the function of BAMs in the acute phase of stroke. We restricted our study to the first hours after stroke to avoid the putative confounding effect of massive macrophage infiltration that takes place in the days that follow stroke [5, $17,47,49,52]$. Moreover, our BAM depleting strategy is transient and repopulation of these cells by peripheral macrophages could follow at later time points. Long-term studies using different experimental approaches are required to understand the consequences of BAM activity for the evolution of the brain lesion and the repair processes, particularly regarding extracellular matrix and vascular remodelling. Another limitation is that we could not separate perivascular from subpial macrophages since all of them express CD163 in the rat brain. Depleting the $\mathrm{CD}_{163}{ }^{+}$macrophage population had more effects in cortical rather than in subcortical regions after ischemia. We suspect that subpial macrophages may play a role by producing VEGF and regulating vascular permeability and extravasation of granulocytes from pial vessels. These effects could exacerbate the brain lesion by impairing the integrity of the collateral circulation [50]. Finally, we conducted our experimental study in young male rats, while stroke mainly affects old people of both sexes. Studies in aged animals and females are required to find our whether BAMs show a similar response in these conditions.

\section{Conclusions}

In summary, this study provides evidence for a role of BAMs in granulocyte chemoattraction and vascular permeability following acute ischemic stroke. The study also suggests that targeting these potentially negative responses of brain resident macrophage might help to preserve cortical blood supply and improve the neurological function in the acute phase of cerebral ischemia/ reperfusion.

\section{Additional file}

Additional file 1: Extended methods, additional tables and figures. (DOCX $6178 \mathrm{~kb})$

\section{Abbreviations \\ A $\beta$ : Amyloid- $\beta$; AMPA: a-amino-3-hydroxy-5-methyl-4-isoxazolepropionic acid; BAMs: CNS border-associated macrophages; CNS: Central nervous system; Cxcl: C-X-C motif chemokine ligand; EAE: Experimental autoimmune encephalomyelitis; Egfr: Epidermal growth factor; FACS: Fluorescence activated cell sorting; HIF-1: Hypoxia inducible factor-1; IL: Interleukin; iNOS: Inducible nictric oxide synthase; IPA: Ingenuity Pathway Analysis; LPS: Lipopolysaccharide; MCA: Middle cerebral artery; MCAo: MCA occlusion; PBS: Phosphate-buffered saline; Th2: T helper type 2; VEGF: Vascular endothelial growth factor}

\section{Acknowledgements}

We are indebted to Dr. Ellen Gelpí for expert neuropathological analysis of human brain tissue, and to Clara Castellví and Alba Hernández for help in image analysis and immunofluorescence, respectively. We acknowledge technical support of the Imaging, Cytomics and Genomics core facilities of the Institut d'Investigacions Biomèdiques August Pi i Sunyer (IDIBAPS), the Confocal Microscopy Unit of the Serveis Cientifico-Tècnics of the School of Medicine-University of Barcelona, and the Bioinformatics and Biostatistics Unit of Vall d'Hebron Research Institute. We thank the Neurological Tissue Bank of the Biobank-Hospital Clínic-IDIBAPS for sample and data procurement, and patient's relatives for giving consent to the use of brain samples for research purposes.

\section{Funding}

Supported by the Spanish Ministerio de Economia y Competitividad (SAF201456279-R and SAF2017-87459-R). JP and MG were supported by a PhD fellowship from the Catalan Research Agency (AGAUR) and the ITN program of the European Community (Neurolnflammation, FP7-PEOPLE-2013-ITN-n 607962), respectively. FMM is recipient of an ICT award by the Pla estratèic de recerca $i$ innovació en salut (PERIS) of the Departament de Salut, Generalitat de Catalunya.

\section{Availability of data and materials}

The RNA microarray data are accessible from the GEO repository of the National Center for Biotechnology Information, U.S. National Library of Medicine (code: GSE106931) (https://www.ncbi.nlm.nih.gov/geo/). Other datasets during and/or analyzed during the current study are available from the corresponding author on reasonable request.

\section{Authors' contributions}

JP and AS performed most experimental animal studies and data analyses; MG carried out cell sorting with input from AG. RC did RNA extraction and validation analyses; FMM designed and supervised flow cytometry studies; FB did the microarray data analysis; CJ supervised the MRI studies; FPA contributed to initial ischemia experiments; LMK performed Western blotting studies; XU and AC facilitated access to human material and provided clinical data; BK contributed in writing; AMP designed the study, analysed data, and wrote the manuscript

All authors read and approved the final manuscript.

\section{Ethics approval and consent to participate}

Animal work was conducted with the approval of the ethical committee of the University of Barcelona (CEEA) and the Direcció General de Polítiques Ambientals i Medi Natural, Departament de Territori i Sostenibilitat de la Generalitat de Catalunya. Studies complied with the "Principles of laboratory animal care" (NIH publication No. 86-23, revised 1985), and the Spanish National law (Real Decreto 53/2013). Animal work is reported according to the ARRIVE guidelines.

The brain tissue of three ischemic stroke patients who died at the Stroke Unit of Hospital Clínic de Barcelona $24 \mathrm{~h}$ after stroke onset was used in this study. We obtained written consent from the families for tissue removal after death for diagnostic and research purposes at the Neurological Tissue bank of the Biobank-Hospital Clínic-Institut d'Investigacions Biomèdiques August Pi 
i Sunyer (IDIBAPS). The study had the approval of the Ethics Committee of Hospital Clínic de Barcelona (CElm).

\section{Consent for publication \\ Not applicable}

\section{Competing interests}

The authors declare that no conflict of interest exists.

\section{Publisher's Note}

Springer Nature remains neutral with regard to jurisdictional claims in published maps and institutional affiliations.

\section{Author details}

'Department of Brain Ischemia and Neurodegeneration, Institut d'Investigacions Biomèdiques de Barcelona (IIBB)-Consejo Superior de Investigaciones Científicas (CSIC), Rosselló 161, E-08036 Barcelona, Spain. ${ }^{2}$ Àrea de Neurociències, Institut d'Investigacions Biomèdiques August Pi i Sunyer (IDIBAPS), Rosselló 161, E-08036 Barcelona, Spain. ${ }^{3}$ Fundació Clínic, Hospital Clínic de Barcelona, Barcelona, Spain. ${ }^{4}$ Statistics and Bioinformatics Unit (UEB), Vall d'Hebron Research Institute (VHIR), Barcelona, Spain. ${ }^{5}$ Department of Genetics, Microbiology and Statistics, Universitat de Barcelona, Barcelona, Spain. 'aboratory of Molecular Neurobiology, Neurobiology Center, Nencki Institute of Experimental Biology, Warsaw, Poland. 'Present address: Institute of Neuroimmunology and Institute for Multiple Sclerosis Research, University Medical Centre Göttingen, D-37073 Göttingen, Germany.

Received: 2 August 2018 Accepted: 4 August 2018

Published online: 09 August 2018

\section{References}

1. Abtin A, Jain R, Mitchell AJ, Roediger B, Brzoska AJ, Tikoo S et al (2014) Perivascular macrophages mediate neutrophil recruitment during bacterial skin infection. Nat Immunol 15:45-53

2. Beck H, Plate KH (2009) Angiogenesis after cerebral ischemia. Acta Neuropathol 117:481-496

3. Bronte V, Zanovello P (2005) Regulation of immune responses by L-arginine metabolism. Nat Rev Immunol 5:641-654

4. Chamorro Á, Dirnagl U, Urra X, Planas AM (2016) Neuroprotection in acute stroke: targeting excitotoxicity, oxidative and nitrosative stress, and inflammation. Lancet Neurol 15:869-881

5. Chamorro Á, Meisel A, Planas AM, Urra X, van de Beek D, Veltkamp R (2012) The immunology of acute stroke. Nat Rev Neurol 8:401-410

6. Coles JA, Myburgh E, Brewer JM, McMenamin PG (2017) Where are we? The anatomy of the murine cortical meninges revisited for intravital imaging, immunology, and clearance of waste from the brain. Prog Neurobiol 156: 107-148

7. Dijkstra CD, Döpp EA, Joling P, Kraal G (1985) The heterogeneity of mononuclear phagocytes in lymphoid organs: distinct macrophage subpopulations in the rat recognized by monoclonal antibodies ED1, ED2 and ED3. Immunology 54:589-599

8. El Kasmi KC, Qualls JE, Pesce JT, Smith AM, Thompson RW, Henao-Tamayo $M$ et al (2008) Toll-like receptor-induced arginase 1 in macrophages thwarts effective immunity against intracellular pathogens. Nat Immunol 9:13991406

9. Enzmann G, Mysiorek C, Gorina R, Cheng YJ, Ghavampour S, Hannocks MJ et al (2013) The neurovascular unit as a selective barrier to polymorphonuclear granulocyte (PMN) infiltration into the brain after ischemic injury. Acta Neuropathol 125:395-312

10. Etzerodt A, Moestrup SK (2013) CD163 and inflammation: biological, diagnostic, and therapeutic aspects. Antioxid Redox Signal 18:2352-2363

11. Evangelista AM, Thompson MD, Bolotina VM, Tong X, Cohen RA (2012) Nox4- and Nox2-dependent oxidant production is required for VEGFinduced SERCA cysteine-674 S-glutathiolation and endothelial cell migration. Free Radic Biol Med 53:2327-2334

12. Fabriek BO, Van Haastert ES, Galea I, Polfliet MM, Döpp ED, Van Den Heuvel MM et al (2005) CD163-positive perivascular macrophages in the human CNS express molecules for antigen recognition and presentation. Glia 51: 297-305
13. Faraco G, Park L, Anrather J, ladecola C (2017) Brain perivascular macrophages: characterization and functional roles in health and disease. J Mol Med (Berl) 95:1143-1152

14. Faraco G, Sugiyama Y, Lane D, Garcia-Bonilla L, Chang H, Santisteban MM et al (2016) Perivascular macrophages mediate the neurovascular and cognitive dysfunction associated with hypertension. J Clin Invest 126:4674-4689

15. Feigin VL, Forouzanfar MH, Krishnamurthi R, Mensah GA, Connor M, Bennett DA et al (2014) Global and regional burden of stroke during 1990-2010: findings from the global burden of disease study 2010. Lancet 383:245-254

16. Gautier S, Ouk T, Petrault O, Caron J, Bordet R (2009) Neutrophils contribute to intracerebral haemorrhages after treatment with recombinant tissue plasminogen activator following cerebral ischaemia. Br J Pharmacol 156:673-679

17. Gelderblom M, Leypoldt F, Steinbach K, Behrens D, Choe CU, Siler DA et al (2009) Temporal and spatial dynamics of cerebral immune cell accumulation in stroke. Stroke 40:1849-1857

18. Goldmann T, Wieghofer P, Jordão MJ, Prutek F, Hagemeyer N, Frenzel K et al (2016) Origin, fate and dynamics of macrophages at central nervous system interfaces. Nat Immunol 17:797-805

19. Gomez Perdiguero E, Klapproth K, Schulz C, Busch K, Azzoni E, Crozet L et al (2015) Tissue-resident macrophages originate from yolk-sac-derived erythromyeloid progenitors. Nature 518:547-551

20. Guo L, Akahori H, Harari E, Smith SL, Polavarapu R, Karmali V et al (2018) $\mathrm{CD}_{163^{+}}$macrophages promote angiogenesis and vascular permeability accompanied by inflammation in atherosclerosis. J Clin Invest 128:1106-1124

21. Gupta P, Lai SM, Sheng J, Tetlak P, Balachander A, Claser C et al (2016) Tissue-resident CD169(+) macrophages form a crucial front line against Plasmodium infection. Cell Rep 16:1749-1761

22. Harris AK, Ergul A, Kozak A, Machado LS, Johnson MH, Fagan SC (2005) Effect of neutrophil depletion on gelatinase expression, edema formation and hemorrhagic transformation after focal ischemic stroke. BMC Neurosci 6:49

23. Hawkes CA, McLaurin J (2009) Selective targeting of perivascular macrophages for clearance of beta-amyloid in cerebral amyloid angiopathy. Proc Natl Acad Sci U S A 106:1261-1266

24. He H, Mack JJ, Güç E, Warren CM, Squadrito ML, Kilarski WW et al (2016) Perivascular macrophages limit permeability. Arterioscler Thromb Vasc Bio 36:2203-2212

25. Herz J, Sabellek P, Lane TE, Gunzer M, Hermann DM, Doeppner TR (2015) Role of neutrophils in exacerbation of brain injury after focal cerebral ischemia in hyperlipidemic mice. Stroke 46:2916-2925

26. Iadecola C, Anrather J (2011) The immunology of stroke: from mechanisms to translation. Nat Med 17:796-808

27. Kida S, Sterat PV, Zhang E-T, Weller RO (1993) Perivascular cells act as scavengers in the cerebral perivascular spaces and remain distinct from pericytes, microglia and macrophages. Acta Neuropathol 85:646-652

28. Kim WK, Alvarez X, Fisher J, Bronfin B, Westmoreland S, McLaurin J et al (2006) CD163 identifies perivascular macrophages in normal and viral encephalitic brains and potential precursors to perivascular macrophages in blood. Am J Pathol 168:822-834

29. Korin B, Ben-Shaanan TL, Schiller M, Dubovik T, Azulay-Debby H, Boshnak NT et al (2017) High-dimensional, single-cell characterization of the brain's immune compartment. Nat Neurosci 20:1300-1309

30. Kreisel D, Nava RG, Li W, Zinselmeyer BH, Wang B, Lai J et al (2010) In vivo two-photon imaging reveals monocyte-dependent neutrophil extravasation during pulmonary inflammation. Proc Natl Acad Sci U S A 107:18073-18078

31. Law SK, Micklem KJ, Shaw JM, Zhang XP, Dong Y et al (1993) A new macrophage differentiation antigen which is a member of the scavenger receptor superfamily. Eur J Immunol 23:2320-2325

32. Lee HS, Han J, Bai HJ, Kim KW (2009) Brain angiogenesis in developmental and pathological processes: regulation, molecular and cellular communication at the neurovascular interface. FEBS J 276:4622-4635

33. Ma Y, Wang J, Wang Y, Yang GY (2017) The biphasic function of microglia in ischemic stroke. Prog Neurobiol 157:247-272

34. Mato M, Ookawara S, Sakamoto A, Aikawa E, Ogawa T, Mitsuhashi U et al (1996) Involvement of specific macrophage-lineage cells surrounding arterioles in barrier and scavenger function in brain cortex. Proc Natl Acad Sci U S A 93:3269-3274

35. Matsuo Y, Onodera H, Shiga Y, Nakamura M, Ninomiya M, Kihara T et al (1994) Correlation between myeloperoxidase-quantified neutrophil accumulation and ischemic brain injury in the rat. Effects of neutrophil depletion. Stroke 25:1469-1475 
36. Mildner A, Schlevogt B, Kierdorf K, Böttcher C, Erny D, Kummer MP et al (2011) Distinct and non-redundant roles of microglia and myeloid subsets in mouse models of Alzheimer's disease. J Neurosci 31:11159-11171

37. Mrdjen D, Pavlovic A, Hartmann FJ, Schreiner B, Utz SG, Leung BP et al (2018) High-dimensional single-cell mapping of central nervous system immune cells reveals distinct myeloid subsets in health, aging, and disease. Immunity 48:380-395

38. O'Neill LA, Kishton RJ, Rathmell J (2016) A guide to immunometabolism for immunologists. Nat Rev Immunol 16:553-565

39. Park L, Uekawa K, Garcia-Bonilla L, Koizumi K, Murphy M, Pistik R et al (2017) Brain perivascular macrophages initiate the neurovascular dysfunction of Alzheimer A $\beta$ peptides. Circ Res 121:258-269

40. Perez-de-Puig I, Miró-Mur F, Ferrer-Ferrer M, Gelpi E, Pedragosa J, Justicia C et al (2015) Neutrophil recruitment to the brain in mouse and human ischemic stroke. Acta Neuropathol 129:239-257

41. Pires PW, Girgla SS, McClain JL, Kaminski NE, van Rooijen N, Dorrance AM (2013) Improvement in middle cerebral artery structure and endothelial function in stroke-prone spontaneously hypertensive rats after macrophage depletion. Microcirculation 20:650-661

42. Polfliet MM, Goede PH, van Kesteren-Hendrikx EM, van Rooijen N, Dijkstra CD, van den Berg TK (2001) A method for the selective depletion of perivascular and meningeal macrophages in the central nervous system. J Neuroimmunol 116:188-195

43. Polfliet MM, van de Veerdonk F, Döpp EA, van Kesteren-Hendrikx EM, van Rooijen N, Dijkstra CD et al (2002) The role of perivascular and meningeal macrophages in experimental allergic encephalomyelitis. J Neuroimmunol 122:1-8

44. Polfliet MM, Zwijnenburg PJ, van Furth AM, van der Poll T, Döpp EA Renardel de Lavalette C et al (2001) Meningeal and perivascular macrophages of the central nervous system play a protective role during bacterial meningitis. J Immunol 167:4644-4650

45. Robinson CJ, Stringer SE (2001) The splice variants of vascular endothelial growth factor (VEGF) and their receptors. J Cell Sci 114:853-865

46. Russell RG, Rogers MJ (1999) Bisphosphonates: from the laboratory to the clinic and back again. Bone 25:97-106

47. Schilling M, Besselmann M, Leonhard C, Mueller M, Ringelstein EB, Kiefer R (2003) Microglial activation precedes and predominates over macrophage infiltration in transient focal cerebral ischemia: a study in green fluorescent protein transgenic bone marrow chimeric mice. Exp Neurol 183:25-33

48. Schoch HJ, Fischer S, Marti HH (2002) Hypoxia-induced vascular endothelial growth factor expression causes vascular leakage in the brain. Brain 125: 2549-2557

49. Schroeter M, Jander S, Huitinga I, Witte OW, Stoll G (1997) Phagocytic response in photochemically induced infarction of rat cerebral cortex. The role of resident microglia. Stroke 28:382-386

50. Shuaib A, Butcher K, Mohammad AA, Saqqur M, Liebeskind DS (2011) Collateral blood vessels in acute ischaemic stroke: a potential therapeutic target. Lancet Neurol 10:909-921

51. Steel CD, Kim WK, Sanford LD, Wellman LL, Burnett S, Van Rooijen $N$ et al (2010) Distinct macrophage subpopulations regulate viral encephalitis but not viral clearance in the CNS. J Neuroimmunol 226:81-92

52. Stevens SL, Bao J, Hollis J, Lessov NS, Clark WM, Stenzel-Poore MP (2002) The use of flow cytometry to evaluate temporal changes in inflammatory cells following focal cerebral ischemia in mice. Brain Res 932:110-119

53. Tanaka R, Komine-Kobayashi M, Mochizuki H, Yamada M, Furuya T, Migita M et al (2003) Migration of enhanced green fluorescent protein expressing bone marrow-derived microglia/macrophage into the mouse brain following permanent focal ischemia. Neuroscience 117:531-539

54. Thanopoulou K, Fragkouli A, Stylianopoulou F, Georgopoulos S (2010) Scavenger receptor class B type I (SR-BI) regulates perivascular macrophages and modifies amyloid pathology in an Alzheimer mouse model. Proc Natl Acad Sci U S A 107:20816-20821

55. van Rooijen N, Sanders A, van den Berg TK (1996) Apoptosis of macrophages induced by liposome mediated intracellular delivery of clodronate and propamidine. J Immunol Methods 193:93-99

56. Yamamoto J, Adachi Y, Onoue Y, Adachi YS, Okabe Y, Itazawa T et al (2000) Differential expression of the chemokine receptors by the Th1- and Th2type effector populations within circulating CD4+ T cells. J Leukoc Biol 68: 568-574

\section{Ready to submit your research? Choose BMC and benefit from:}

- fast, convenient online submission

- thorough peer review by experienced researchers in your field

- rapid publication on acceptance

- support for research data, including large and complex data types

- gold Open Access which fosters wider collaboration and increased citations

- maximum visibility for your research: over $100 \mathrm{M}$ website views per year

At BMC, research is always in progress.

Learn more biomedcentral.com/submissions 